\title{
CAMPO E HEGEMONIA: PROXIMIDADES ENTRE BOURDIEU E GRAMSCI E A ANÁLISE DOS PROCESSOS EDUCACIONAIS
}

\author{
Máximo Augusto Campos Masson*
}

\begin{abstract}
RESUMO: O artigo discute as possibilidades de articulação entre as abordagens teóricas de Pierre Bourdieu e Antonio Gramsci para a análise das sociedades modernas. São comentados conceitos centrais de Bourdieu como campo social e habitus de classe bem como o de hegemonia de Antonio Gramsci, verificando-se a presença de elementos que permitem interrelacionar seus conceitos, ainda que os dois autores tenham orientações teóricas díspares, abrindo novas perspectivas de análise.
\end{abstract}

PALAVRAS-CHAVE: Campo Social. Hegemonia. Pierre Bourdieu. Antonio Gramsci.

\section{FIELD AND HEGEMONY: THE PROXIMITY BETWEEN BOURDIEU AND GRAMSCI AND THE ANALYSIS OF EDUCATIONAL PROCESSES}

\begin{abstract}
This article discusses the possibilities of articulation between the theoretical approaches of Pierre Bourdieu and Antonio Gramsci for the analysis of modern societies and educational processes. We discuss the concepts of social field and class habitus by Pierre Bourdieu and that of hegemony by Antonio Gramsci, verifying the presence of elements that allow interrelating their concepts, opening new perspectives of analysis, even though the two authors have disparate theoretical orientations.
\end{abstract}

KEYWORDS: Social Field. Hegemony. Pierre Bourdieu. Antonio Gramsci.

\section{CAMPO Y HEGEMONÍA: PROXIMIDAD ENTRE BOURDIEU Y GRAMSCI Y EL ANÁLISIS DE LOS PROCESOS EDUCATIVOS}

RESUMEN: El artículo discute las posibilidades de articulación entre los enfoques teóricos de Pierre Bourdieu y Antonio Gramsci para el análisis de las sociedades modernas y los procesos educativos. Se comentan los conceptos centrales de Bourdieu como campo social y habitus de clase, así como el de la hegemonía de Antonio Gramsci, comprobando la presencia de elementos, aunque los dos autores tienen orientaciones teóricas diferentes, lo que permite interrelacionar sus conceptos. abriendo nuevas perspectivas de análisis.

ALABRAS CLAVE: Campo Social. Hegemonía. Pierre Bourdieu. Antonio Gramsci.

\footnotetext{
* Bacharel e licenciado em ciências sociais (UFRJ), mestre em ciências sociais (UFRJ), doutor em educação (UFRJ), com estágio de pós-doutorado em educação (USP). Professor Associado da UFRJ e do Programa de Pós-graduação em Educação, Contemporaneidades e Demandas Populares da UFRRJ.

E-mail: maxmasson@ufrj.br/Orcid: https://orcid.org/0000-0001-7205-3871
} 


\section{Introdução}

O conceito de campo em conjunto com os de espaço social, habitus, distinção e estratégia integram o instrumental teórico produzidos por Bourdieu para construir uma teoria da prática social ${ }^{1}$ (BOURDIEU, 1983 e 1989, 2009), possibilitando melhor apreensão da complexidade do processo educacional nas diversas sociedades modernas $^{2}$, da constituição das instituições e agentes pertinentes a esse processo (escolas, professores, integrantes de equipes pedagógicas, estudantes e seus familiares) e das transformações ocorridas na história desse processo.

Se temos por intenção primeira melhor compreender a progressiva configuração do campo educacional como campo social dotado de relativa autonomia frente a outros $\operatorname{campos}^{3}$ e, em segundo lugar, apreender características dos processos educacionais a que estão submetidos, sob diversas formas aqueles agentes que assumem nas instituições desse campo, por exemplo, a condição de estudantes ou de professores, devemos ressaltar um postulado sociológico, por vezes pouco lembrado: os agentes sociais somente ganham uma existência social, isto é, passam a ser uma realidade socialmente concreta, quando incursos e posicionados no interior de instituições de uma dada sociedade. Nas instituições, os agentes estabelecem obrigatoriamente interações com outros nelas presentes, o que lhes possibilita assumir uma identidade social, que vem a ser construída em meio aos efeitos conformadores e constituintes da violência simbólica que é subjacente a todas as instituições. Violência que é exercida, de modo mútuo, contínuo e comumente inconsciente pelos próprios agentes que se encontram nessas instituições.

Assim sendo, a existência de uma instituição somente se concretiza por força das ações dos agentes, ainda que esses não as construam ao dispor das suas vontades ${ }^{4}$, mas sob as condições particulares e estruturalmente determinadas que todo campo social vem a possuir, fruto da própria história desse campo. Portanto, são as propriedades particulares de um dado campo que fazem com que os agentes

\footnotetext{
${ }^{1} \mathrm{O}$ construto conceitual de Bourdieu possibilita incorporar ou aproximar categorias desenvolvidas por outros autores, como em especial, Norbert Elias (o que foi inclusive objeto de comentário do próprio Bourdieu (BOURDIEU e CHARTIER, 2011), como também da analise marxista, em particular as formulações sobre hegemonia produzidas por Gramsci, como salientou Burawoy (2010).

${ }^{2}$ Designamos por sociedades modernas aquelas em que se afirmam de maneira plena a individuação como modo dominante de constituição do tipo de agente social predominante. Nesse processo atua de maneira intrínseca e cada vez mais ampla e abrangente a escola.

${ }^{3}$ Os campos sociais que integram um dado espaço social encontram-se interseccionados entre si e em permanentes relações. A configuração da autonomia, em algum grau, de um campo frente aos demais, em particular ao campo econômico, é resultado de processos históricos particulares a cada espaço social, a cada sociedade. O conceito de campo social é um conceito de caráter geral, porém, na análise de uma realidade social específica não devemos empregá-lo de maneira formal e abstrata, desconsiderando particularidades históricas dessas realidades, perdendo-se com isto toda possibilidade de utilizá-lo para uma apreensão mais efetiva da complexidade dessa sociedade e dos campos nela existentes e das relações entre os mesmos.

${ }_{4}$ Tal como na conhecida expressão de Marx no 18 do Brumário: Os homens fazem a sua própria história, mas não a fazem segundo a sua livre vontade; não a fazem sob circunstâncias de sua escolha e sim sob aquelas com que se defrontam diretamente, legadas e transmitidas pelo passado (MARX, 2002, p. 21).
} 
sociais assumam principalmente ou a condição de produtores especializados da violência simbólica, isto é, de terem a capacidade de definição dos ritos e discursos que conformam as práticas próprias desse campo ou a de consumidores desapossados de instrumentos necessários para responder à violência simbólica institucional existente e criar novas formas desta se conformar.

Deste modo, o existir dos agentes ocorre incurso em um jogo de forças delimitado por estruturas que são objetivamente estruturantes do seu agir, mas que, ao mesmo tempo são subjetivamente estruturadas, quer dizer, sofrem os efeitos das ações dos agentes, numa complexa relação dialética, conforme analisa Bourdieu (1989) ${ }^{5}$.

Nesse sentido, a construção de um objeto sociológico deve ter em conta a gama de relações que se estabelecem não só no interior de cada campo social como entre os diversos campos. Relações que são fundamentais para a definição tanto dos limites de cada campo como para os possíveis modos de ação dos agentes sociais no interior destes.

\section{Construção do objeto e objetivação do conhecimento}

Contudo essas relações não se apresentam com a imediaticidade que o empirismo, seja este mais ou menos sofisticado, vem a conceber quando transmuta as noções veiculadas pelo senso comum em características de objeto de estudo, fazendo do que se enuncia na doxa presente nos discursos dominantes a diretriz do processo investigativo. O proceder empiricista, além de secundarizar a importância analítica das relações entre os vários campos sociais para o desenvolvimento do entendimento sociológico ${ }^{6}$, termina por subentender o objeto de pesquisa como um ente, por essência, concreto e encontradiço no mundo social. Em outras palavras, concebe o objeto como um fenômeno cujo contorno deveria ser rigidamente delineado, à moda dos preceitos ou, porque não dizer, preconceitos da ortodoxia positivista.

No entanto, a definição de um objeto de pesquisa não pode ser vista como uma identificação empírica empreendida pelo sujeito que, em decorrência única do processo de observação imediata, realizaria um recorte do real, dele extraindo o fenômeno a ser conhecido. Como lembrava Bachelard: "...o objeto não pode ser designado como um ‘objeto imediato', por outras palavras, um movimento para o objeto não é inicialmente objetivo... a adesão imediata a um objeto concreto apreendido como um bem,

\footnotetext{
${ }^{5}$ Devemos ressaltar que esse jogo de forças em que os agentes sociais se encontram inseridos, em sociedades desigualmente estratificadas tende a se configurar como relações de luta entre classes e frações de classe e também no interior destas. Marx ao diferenciar o modo de agir dos capitalistas quando voltados para assegurar interesses pessoais, notadamente os esforços e as lutas que fazem individualmente para conseguir que suas empresas acumulem o capital necessário para sobreviverem em meio à concorrência inerente ao mercado econômico, sinalizava para as lutas internas que seriam inerentes à classe burguesa, fossem essas lutas a no interior de uma dada fração de classe, situação que poderia levar a constituição de monopólios ou oligopólios privados, fossem entre frações distintas da burguesia, por exemplo, industriais contra banqueiros.

${ }^{6}$ Em especial, no âmbito das pesquisas educacionais, perspectivas empiricistas tendem ou a circunscrever o objeto de estudo à esfera mais imediata de seu local de emergência, desconsiderando o complexo quadro de relações próprias do campo educacional ou a estabelecer relações imediatas e diretas com elementos situados em outros campos sociais, num reducionismo mecânico.
} 
utilizado como um valor compromete demasiado intensamente o ser sensível, é a satisfação íntima, não é a evidência racional" (BACHELARD, 1984, p. 128, grifos do autor).

A redução do objeto científico ao objeto concreto redunda, portanto, no escamotear das perspectivas axiológicas que atuam implicitamente no processo de definição do primeiro.

O objeto científico é resultante de um processo de construção só viabilizado por meio de uma operação de ordem teórica onde o emprego de certo instrumental conceitual, de modo metódico, se constitui no elemento possibilitador de sua determinação. Os conhecimentos científicos somente podem resultar da presença constante de um conjunto de referenciais, os quais não são outra coisa senão a teoria. Ela é a responsável por informar e delimitar as questões que se fazem presentes no cotidiano das práticas científicas.

A incompreensão da importância da teoria se apresenta, de modo perfeito e sub-reptício, em um sem-número de "disfarces metodológicos" empregados no intuito de promover - constantemente por intermédio de apelos aos postulados fenomenológicos - um pseudo-afastamento de posições declaradamente empiristas. Aliás, é comum, especialmente entre pesquisadores do campo educacional, definir-se restritamente como pertinentes a posições empiristas, os estudos em que é há algum tipo de valoração do uso de técnicas da análise estatística, fazendo com que as chamadas pesquisas quantitativas sejam, por princípio, classificadas como empiristas ou empiricistas. Esse tipo de entendimento simplório ao igualar empírico a empirismo, não executa um dos mais importantes procedimentos metodológicos na prática científica, qual seja a ruptura com as "taxionomias pré-construidas on formais" (BOURDIEU, 1982, p. 186), norteadoras das análises marcadas pela alheação empiricista, sejam elas "quantitativas ou qualitativas".

Por não serem apenas conjuntos aleatórios de reflexões articuladas sobre determinados fenômenos, mas, ao contrário, por exercerem a condição de elemento decisivo e imprescindível em qualquer tentativa de investigação precisa, os dispositivos teóricos cumprem, na formulação das problemáticas da pesquisa, um papel de crucial importância para o conhecimento. Este papel assume um duplo aspecto, cuja dialética configura a trajetória da produção dos conhecimentos.

O primeiro aspecto é de caráter eminentemente positivo: ser dinamizador, impulsionador e viabilizador da produção de novas verdades, pois que o saber científico não é contemplativo, mas sim realizador. É a partir da teoria que se questionam as certezas, que o senso comum - inclusive o "senso comum douto" - desconsidera ser conveniente duvidar. Também por seu uso é que podem ser construídas retificações no conhecimento anterior, sempre sucessivas, embora não-cumulativas, promotoras das mudanças de enfoque e perspectiva quanto à natureza do objeto.

É graças ao uso meticuloso das teorias, pelo "conhecer o método de conhecer para captar o objeto a conhecer" (BACHELARD, 1977), que se constrói o conteúdo das indagações científicas, a formalização de novos problemas a serem trabalhados e resolvidos, a construção de novas temáticas. 
Pela a teoria torna-se possível a formulação de hipóteses dotadas de uma estrutura nocional (BACHELARD, 1984), radicalmente distante de intuições ingênuas que não mais protagonizam senão o reconhecimento de verdades passadas e incrustadas. Em especial, é através da teoria que se pode abandonar toda e qualquer pretensão de pensar a realidade como passível de ser formulada em conceituações simples. O real nunca é simples, não vem a ser composto pela justaposição de elementos atomizáveis. Abstrata síntese de múltiplas determinações, segundo a conhecida expressão de Marx, a "imagem conceitual" de um objeto científico é estruturalmente dotada de complexidade relacional, pois o conhecimento que aparenta ou advoga para si uma simplicidade estrutural, na verdade, afigura-se ainda na condição de um "não-conhecimento", de um mal pensar o complexo. Produto de uma problemática mal formulada que precisa ser superada para que as próprias ciências venham também a se superar (BACHELARD, 1977; 1990).

O segundo aspecto do papel dos dispositivos teóricos caracteriza-se por ser negador do desenvolvimento continuado da produção do conhecimento científico. Decorrente da força que lhe é específica e intrínseca, toda teoria que se revela analiticamente fecunda pode, no correr da rota normal das pesquisas que a ela se fazem adstritas (KHUN, 1987), tender a bloquear as possibilidades de indagação sobre aspectos não-apreendidos ou resolvidos pelas formulações teóricas em vigor, vindo a se constituir em obstáculo ao conhecimento.

Seguindo-se ainda a Bachelard, podemos afirmar que somente pela problematização da teoria existente e dos próprios intentos ou mesmo divagações do investigador, poder-se-á superar os entraves colocados por esta forma de obstáculo epistemológico, muito mais sutil e eficaz em seus efeitos obstaculizadores do que as afirmações "grosseiras" do senso comum.

Obstáculo eficaz porque, aludindo às verdades formuladas sobre o real, iludiria o pesquisador ao lhe impor - geralmente de forma inconsciente - no transcurso de sua formação acadêmica, a delimitação do perímetro em que se encontra o conjunto de paradigmas estabelecidos. Aqueles, nos quais pode transitar sem os riscos da desautorização dos seus pares, visto que já de antemão, encontrou definido o que é possível, legitimamente, o seu pensamento pensar, uma vez que é: "sobretudo através das problemáticas obrigatórias nas quais e pelas quais um pensador reflete que ele passa a pertencer à sua época podendo-se situá-lo e datá-lo" (BOURDIEU, 1982, p. 207).

Assim, o tornar público, do modo mais explícito possível, os pressupostos teóricos de onde acreditamos partir - não para afastá-los na busca da negação de sua intervenção cognoscente, mas para interrogá-los sistematicamente - permite-nos delinear a problemática na qual se processará a produção do objeto a ser conhecido. Verdades científicas não são conhecimentos totais e absolutos que devam ser alcançados pelo pesquisador. São, ao contrário, unicamente conhecimentos expressos sob a forma de discursos delongadamente construídos no esforço dos erros produzidos, das respostas que indicam tanto a inflexão dos esquemas cognitivos como a intenção e a necessidade de construir novos percursos intelectuais. 
O intento de um processo de investigação é a produção de conhecimentos, cujos graus de veracidade, estatuto de cientificidade e validade devem ser sempre os mais abrangentes e redimensionadores possíveis das verdades afirmadas, até atingir-se o ponto de sua negação, que possam perscrutar novas bases epistêmicas.

Entretanto, não se pode tomar como garantia de cientificidade o reconhecimento inicial que o sujeito pesquisador possa fazer acerca dos valores que em sua mente, em suas percepções primeiras, se encontrariam internalizados e que poderiam intervir no processo de constituição do objeto que pretende investigar e conhecer. Isto não é condição suficiente para a produção do conhecimento de aspiração científica.

Prescinde ter-se, a todo o momento, como fim desejável, por meio da vigilância intelectual sobre si mesmo (BACHELARD, 1977), a objetivação do conhecimento, assumida como parte integrante dos procedimentos investigatórios. Do contrário, afirmaríamos desde já a instituição das evidências, mesmo daquelas que aparentam surgir em meio à prática científica, e que são entraves a qualquer possível novo saber.

O descuido com a objetivação possibilita que o conhecimento afirmado nada mais seja do que a reordenação, sob nova forma, de uma verdade não somente anteriormente pronunciada, como de imediato identificada, antes mesmo de se processar o principiar da pesquisa. Limitaríamo-nos, se assim o procedermos, ao exercício de referendar nossa própria ideologia, aqui compreendida em seu significado restrito de visão mistificadora do real, alimentando o poder de um discurso que teria sua força na reprodução constante e ritualística de seus ditos; na aclamação das suas "verdades" como verdades objetivas e objetivadas por meio da autoridade de quem as fala, mesmo quando estas são apresentadas como "verdades relativas".

Em suma, terminaríamos, ainda que desejássemos de todo nos afastar das aporias da filosofia do conhecimento, por tornarmo-nos, invariavelmente, prisioneiros dos velhos dilemas das polêmicas entre o nominalismo e o realismo. Como afirma Bourdieu, para a construção de um objeto científico é preciso que o pesquisador execute o difícil procedimento - em absoluto distinto de uma velada e sofisticada reafirmação de atitudes de neutralidade quanto aos valores - de renunciar, dentro dos limites em que isto vier a ser possível, "a tentação de se servir da ciência para intervir no objeto, para se operar uma objectivação que não seja a simples visão redutora e parcial que se pode ter, no interior do jogo, de outro jogador, mas sim a visão global que se tem de um jogo passível de ser apreendido como tal porque se saiu dele" (BOURDIEU, 1989, p. 58).

Ser bem sucedido em tal empreitada, em boa parte decorre do como empregamos as "ferramentas do pensamento", herdadas do acervo teórico que faz parte de nosso legado intelectual e, igualmente, de estar também atento às armadilhas que podem acompanhar essas "ferramentas". 
Nesse sentido, é de grande utilidade o recurso ao devir histórico e consequentemente à contextualização histórica. Por este, torna-se possível evitar incorrer-se em um substancialismo abstrato, segundo o qual as categorias analíticas (os conceitos científicos) seriam transcendentes à história.

O atentar para a história sob uma perspectiva não-teleológica impõe, primeiro, a crítica ao uso formalista, para não dizer fetichista, dos conceitos, onde domina "a propensão para considerar os instrumentos "teóricos"... em si mesmos, em vez de os fazer funcionar, de os por em ação" (BOURDIEU, 1989, p. 27). Segundo, exige um pensar "relacional". Tal pensar deve ter por perspectiva investigatória primeira a construção histórica das "redes de relações de oposição e concorrência" (BOURDIEU, 1989, p. 30), que ligam um objeto ao conjunto dos demais elementos integrantes dos campos sociais. Estes, como dito acima, são dotados de estruturas estruturadas e estruturantes (BOURDIEU, 1989), que abrange e circunscreve o objeto.

Ao mesmo tempo, o exercício crítico da teoria necessita garantir para si a construção de suas condições de realização mediante o historicizar dos conceitos que se pretende empregar. É "descobrindo sua própria historicidade que a razão obtém os meios para escapar à história" (BOURDIEU, 1990, p. 38), em suas determinações mais inconscientes. Exatamente por ter como referência inicial a historicização dos agentes e de suas estratégias, das estruturas onde estão inscritos e dos conceitos a estes relativos, em outras palavras, por entender que há em todas estas três dimensões - dos agentes, das estruturas e dos conceitos- uma gênese social, que a obra de Bourdieu não pode ser caracterizada, como uma variação estruturalista ou ultrarelativista, cujos resultados finais seriam a legitimação cientificista da perpetuação do status quo ou a acalentação dissimulada de um ceticismo epistemológico generalizado, no qual a presença dos interesses interditaria a positividade ou objetividade de qualquer conhecimento, visto que todo saber, em última instância, seria arbitrário.

Essas maneiras de conceber a análise de Bourdieu se constituem em grandes equívocos interpretativos, que somente - e de maneira também profundamente equivocada - permite lançar-lhe a costumaz pecha de reprodutivista ou acusá-lo de construir uma argumentação ilógica, onde a pretensa objetividade da sua análise somente seria alcançada mediante o recurso a um golpe de mão: o advogar exclusivamente para si, numa metamorfose auto-afirmativa, a interpretação científica da realidade ${ }^{7}$

Dessa maneira, "escapar à história" não significa, para Bourdieu, sobrepor-se ao mundo das relações sociais, como se o pesquisador pudesse, pelos seus acertos metodológicos, levitar sobre os interesses e guindar-se a ter por mestre condutor do processo de sua pesquisa, uma transcendente razão universal. Muito ao contrário, este "escapar" passa por opor-se radicalmente ao desconhecimento de que o mundo social, nele incluídos os espaços onde são produzidos os discursos sobre o mesmo, principalmente os sociológicos, se constitui em campos de luta permeados de história, onde, poderíamos dizer parafraseando-se a Marx, os fantasmas do passado (e do presente) assaltam o cérebro dos homens.

\footnotetext{
${ }^{7}$ Exemplares neste tipo de incompreensão e má interpretação do complexo quadro teórico de Bourdieu são os comentários expressos em Cunha (1980) e Ferry e Rebaut (1988).
} 


\section{Teoria da prática social e o conceito de campo social}

Por atentar para a historicidade do social e dos conceitos a ele relativos, a proposição de uma teoria da prática social procura ser uma alternativa ao dilema presente e constituinte de toda a história das ciências sociais: a antinomia entre o subjetivismo e o objetivismo (BOURDIEU, 1989).

A construção de uma teoria da prática social, proposta por Bourdieu, busca, primeiro, proceder a uma ruptura com as tradições das filosofias do sujeito, caras às formulações fenomenológicas inspiradoras do interacionismo simbólico, da etnometodologia e do marxismo analítico, que tendem a tomar, em maior ou menor grau, por universais suas representações de uma construção particular e histórica: a do indivíduo dotado da racionalidade própria à vida social moderna.

Em segundo lugar, a proposta de Bourdieu também se apresenta como um contraponto à tradição estruturalista. Nesta, graças ao privilégio ontológico da categoria de estrutura, os agentes, visto serem definidas suas disposições exclusivamente como efeitos estruturais, são reduzidos ao papel de suportes dessas mesmas estruturas (BOURDIEU, 1989).

Sob a condição de compreensão alternativa ao estruturalismo objetivista e ao subjetivismo fenomenológico, a sociedade é concebida por Bourdieu como um campo:

o campo social é um espaço multidimensional, conjunto aberto de campos relativamente autônomos, quer dizer, subordinados quanto ao seu funcionamento e às suas transformações de modo mais ou menos firme e mais ou menos directo ao campo de produção econômica: no interior de cada um dos subespaços, os ocupantes das posições dominantes e os ocupantes das posições dominadas estão ininterruptamente envolvidos em lutas de diferentes formas (sem por isto se constituírem necessariamente em grupos antagonistas) (BOURDIEU, 1989, p. 153, (grifo nosso).

Deste modo, o campo social não é um espaço amórfico, a ser moldado pelo subjetivismo da vontade dos agentes, mas sim, como antes anunciado, local da ação de forças sociais, histórica e objetivamente estruturado. Porém, de modo diverso ao pensamento estruturalista, as práticas dos agentes, segundo a perspectiva de Bourdieu, incidem efetivamente na estruturação desse espaço estruturante.

Tem-se, por esta definição, uma representação metafórica do espaço social de dupla face. Uma, topológica, geográfica: espaço configurando por regiões ou subespaços (os campos particulares), dotados de autonomia relativa frente uns aos outros e subordinados, também por uma mediação indireta, ao campo econômico. Outra, física: espaço como campo de forças, que, de modo objetivo, impõe dinamicamente propriedades específicas aos agentes.

A representação topológica, por ter como principais as categorias de autonomia relativa e subordinação, remete-nos inevitavelmente a outro dilema igualmente intrínseco à trajetória das teorias sociológicas: o do determinismo. 
Ante as infindáveis controvérsias exegéticas ${ }^{8}$ da tradição marxista sobre o poder determinador, em última instância, atribuído às relações econômicas (sobretudo no que diz respeito aos efeitos decorrentes das contradições entre as forças produtivas e as relações de produção) e ao distanciamento imaginário dos efeitos concretos do campo da produção econômica, defendido por toda sorte de neoidealismos ultrarelativizadores, a proposta de Bourdieu intenciona apreender os graus de autonomia relativa dos diversos e possíveis campos constituintes do espaço social para com o campo econômico.

Embora aparentasse pretender ser uma ruptura crítica com o marxismo, especialmente no tocante à conceituação de classe social, a abordagem de Bourdieu, em especial no curso de suas últimas obras, em muito daquele se aproxima, pois está centrada numa problemática, que ressalvadas algumas considerações terminológicas, é cara à tradição da analítica marxista. Sublinhe-se que, ao contrário de perspectivas fundamentadas ou influenciadas, de alguma maneira, pelas interpretações althusserianas, para Bourdieu não se trata de conceber as relações entre os diferentes campos e a autonomia relativa face ao campo econômico como desde sempre estruturadas sob limites circunstancialmente dados, mas sim as apreender como processualmente constituídas, portanto, historicamente produzidas. Deste modo, a configuração das estruturas dos campos, enquanto uma resultante histórica, não é anterior aos agentes? .

Os campos se constituem no processo das relações sociais, não necessariamente vêm a antecedêlas. A importância dada à processualidade histórica na compreensão dos campos e de suas estruturas é igualmente presente na representação destes como "campo de forças".

Pensar os campos como espaços onde os agentes estabelecem entre si relações de força, proporciona a compreensão das estruturas dos primeiros como um estado dado por essas relações de força, podendo, assim, estar sujeita a transformações. Mas a estrutura de um campo, se suscetível à ação interveniente dos agentes, é, por sua vez, definidora das propriedades de funcionamento deste. Estas propriedades de funcionamento se constituem no modo de distribuição das diversas formas de capital (econômico, cultural, simbólico), que torna possível a distinção social e a divisão hierárquica dos agentes. Distinção que se define por um princípio básico: a posse diferenciada da forma de capital estrategicamente singular a cada respectivo campo.

Desse modo, as propriedades historicamente constituídas de funcionamento de um campo social são responsáveis pela disposição em seu interior dos lugares (posições) ocupados pelos agentes sociais, das relações entre estes e pela definição dos interesses que lhes são comuns e fundamentais. Como as disposições dos agentes se estabelecem absolutamente interligadas, gravitando em torno à monopolização do objeto de distinção social (a forma de capital especificamente dominante no campo), os campos são obrigatoriamente pautados pela disputa sobre a posse dessa forma de capital, tornando-os, por força

\footnotetext{
8 Controvérsias que, por não raro fazerem do social um epifenômeno imediato do econômico, alimentaram (ou ainda alimentam) um leque de dogmatismos que se estende do economicismo mais mecanicista ao voluntarismo mais pretensioso. ${ }^{9}$ É sintomático a presença de autores marxistas em números de Actes de la Recherche en Sciences Sociales, entre os quais podemos destacar E. P. Thompson, um grande crítico da abordagem de Althusser (THOMPSON, 1981).
} 
desta mesma disputa, imprescindivelmente: "um lugar de uma luta mais ou menos declarada pela definição dos princípios legítimos de divisão do campo" (BOURDIEU, 1989, p. 150).

O caráter dos conflitos no interior dos campos possibilita que a realidade seja compreendida em um nível que escapa aos estudos tomados a partir de uma "teoria da resistência cultural", visto que nesta última falta um detalhe de grande importância: o reconhecimento que a cultura dos socialmente dominados também se estrutura em campos não-estanques, abandonando-se o debate interminável sobre a plena absorção pelos dominados da cultura dominante - mesmo que sob as formas degradadas da indústria cultural - ou das condições de efetivação de sua "pureza".

Ao conceituarmos a cultura dos dominados como estruturada no interior dos campos sociais, podemos compreender as estratégias de distinção empregadas por alguns desses agentes, em geral através de um mimetismo da cultura dos dominantes, não como uma simples "contaminação" ideológica, mas um empreendimento de promoção social, mesmo quando restritamente simbólica. Tentativas, sob condição e oportunidade socialmente favoráveis, de auferir determinados bens cuja apropriação lhes é comumente negada, quase sempre determinadas formas de capital cultural objetivado como diplomas escolares, afora os decorrentes ganhos em termos de capital econômico advindos da sua posse.

De modo similar, o conceito de campo permite-nos escapar do beco sem saída teórico do multiculturalismo, isto é, da contaminação ideológica das "culturas separadas", onde as subordinadas "resistem" ao domínio ideológico das dominantes, levado a efeito pelo controle dos meios de comunicação de massa e outras instituições, principalmente, as escolas e as igrejas. Prender-se a um substancialismo ideológico das classes é desconhecer que a "cultura" dessas classes, muito especialmente nas sociedades modernas ou ocidentalizadas, resulta das relações sociais que as constituem concomitantemente, não sendo decorrentes de uma justaposição ou "encontro" entre culturas que, em essência, seriam inicialmente distintas.

É importante sempre ressaltar que, na perspectiva aberta por Bourdieu, a constituição de um campo social autônomo, ou seja, dotado da autonomia relativa frente aos demais campos, em particular ao econômico, traz por consequência a questão da definição de formas socialmente legítimas de empreender-se a luta neste campo. Esta, ao se realizar legitima a autonomia do próprio campo.

Nesse sentido, a luta se configura sob a forma de um jogo de atos e atitudes, a circular entre a ortodoxia - forma consagrada de agir - e a heresia - estratégia de ruptura crítica, subvertedora do modo de distribuição do poder no interior do campo - ambas decorrentes do reconhecimento pelos agentes de regras e crenças - os ritos de passagem e iniciação ou, no próprio dizer de Bourdieu, de instituição (BOURDIEU, 1982; 1996) - particularmente necessárias ao ingresso e à permanência no campo.

É através das regras e crenças pertinentes a determinado campo social que se realiza, de modo próprio a este, a nomeação específica da realidade, prescrevendo-se um acordo, por vezes inconsciente, entre os antagonistas sobre o que está sendo, de fato, posto em disputa. Situados nesses espaços de luta, os agentes sociais, no correr de seus enfrentamentos mútuos, constroem estratégias próprias de atuação, 
estruturalmente orientadas, que objetivam a monopolização interna dos símbolos e significados institucionais, produzida pelo apossar-se dos objetos de distinção, isto é, do capital específico de cada campo.

A luta por essa monopolização, que se realiza mediante o emprego de instrumentos autorizados - portanto também socialmente legitimados - de exercício da violência (simbólica ou física), implica em permanente esforço para impedir, pela desqualificação de suas pretensões, que agentes concorrentes venham a ser capazes de ou apoderarem-se desse capital ou tornarem-no ilegítimo, ameaçando, assim, posições de domínio no campo já alcançadas ou em vias de serem conquistadas dentro de um campo social. No entanto, isto não significa que o agente social haja sempre de forma consciente e racionalmente orientado pelo interesse objetivo de galgar posições no campo, fazendo das pressões decorrentes de valores morais internalizados uma mera justificativa ideológica e de todo agente social um cínico ${ }^{10}$.

Se um campo social se define por um objeto de disputa e pelos interesses específicos de consagração social relacionados à posse desse objeto, torna-se, consequentemente, um pressuposto básico da configuração de um campo, a presença de agentes aptos e prontos a travar as lutas singulares ao campo, estabelecendo-se, segundo Bourdieu, como condição sine qua non a todo agente social ser dotado de habitus de classe.

\section{Habitus de classe e estratégia}

Conceito estratégico em sua teoria da prática social, pois que desenvolvido para superar a antinomia estrutura - agente, o babitus de classe se constitui em um "sistema de disposições adquiridas pela aprendizagem implícita ou explícita que funciona como um sistema de esquemas geradores, é gerador de estratégias que podem ser objetivamente afins aos interesses objetivos de seus autores sem terem sido expressamente concebidas para este fim" (BOURDIEU, 1983b, p. 94) ou que impliquem no conhecimento e "no reconhecimento das leis imanentes do jogo, dos objetos de disputas, etc." (BOURDIEU, 1983b, p. 89).

Produto histórico das relações do espaço social, o habitus de um agente tem por referência o "sistema de disposições inconscientes" (BOURDIEU, 1982, p. 201), particulares à sua posição no campo social e que foram objetivamente internalizadas pelo processo de socialização ao qual foi sujeitado. Esse sistema de disposições é possibilitador dos "sistemas de classificações que preexistem (logicamente) às representações sociais do real” (BOURDIEU, 1983, p. 16). Pela via dessas disposições inconscientes, o habitus é "princípio unificador e gerador de todas as práticas" (BOURDIEU, 1982, p. 201), e consequentemente, das estratégias do agente.

\footnotetext{
10 A luta por interesses no campo não é uma mera demonstração de cinismo, na medida em que boa parte dos agentes desconhece os seus efetivos interesses no campo ou os fantasiam.
} 
A internalização do habitus permite ao agente não apenas tomar as suas representações do real e as suas relações com os demais agentes como naturais ${ }^{11}$, porém, muito além disso, dota as suas práticas de uma desenvoltura (quanto ao gosto, ao porte, ao falar, etc.) inimitável por aqueles que se encontram diferentemente posicionados no campo social. Desenvoltura dada pela naturalidade distintiva propriedade de todo babitus - que possibilita afirmar ou negar a legitimidade dos interesses e da posição social do agente social, de modo aparentemente irreversível.

O habitus de um agente expressa a distância que este se encontra do proceder legitimamente prescrito no campo. Proceder que vem a ser o sempre diversificado exercício, próprio aos ocupantes das posições de maior domínio e respeitabilidade no campo social, da distinção, isto é, da busca contínua pelo diferenciar-se o mais completamente possível dos posicionados hierarquicamente na condição de dominados ou subalternos. A distinção se concretiza, enquanto um processo de legitimação social dos dominantes, pela desnaturalização de determinados modos de agir (comuns aos subalternizados no campo) e naturalização de outros, nos quais se acumulou mais significativamente o capital distintivo específico ao campo, como resultado das lutas que nele foram e são travadas. Muito logicamente são as crianças que mais se encontram despercebidamente envolvidas nesse jogo de naturalização/desnaturalização de atitudes. Jogo que termina por ser um exercício rigoroso de autodisciplina, de autocontrole, altamente intensificado com a consolidação do processo de individuação nas sociedades modernas.

Como as propriedades e disposições configuradoras do babitus de todo agente dependem das ações dos demais agentes presentes em cada campo, a posição de um agente no espaço social é definida pelo conjunto das posições que este venha a ocupar nos diferentes campos constituintes deste espaço. Assim, as inter-relações entre as estruturas dos campos e o babitus delimitam as trajetórias que, a princípio, os agentes podem ou poderão vir a realizar, mediante as estratégias que empregarem. Em outras palavras, essas inter-relações (entre estruturas e habitus) estabelecem as coordenadas do modo como os agentes irão atuar nos campos, jogando o jogo social que ali é jogado, mas ao mesmo tempo, desde que capacitados para tal, isto é, situados em posição e condição propícias, podem desenvolver estratégias de ruptura das regras do jogo e se bem sucedidos, iniciarem um novo jogo, cuja forma de jogar, poderá ser também igualmente nova.

Ao contrário, portanto, de interpretações que a consideram ser uma apreensão unicamente estática e sincrônica das relações sociais, onde os processos de mudança seriam impossíveis, uma vez que as ações dos agentes sempre se encontrariam totalitariamente pré-estabelecidas pelo babitus, configurando-se, de antemão, os percursos ou trajetos a serem teleologicamente cumpridos em virtude

\footnotetext{
11 Observe-se que se o babitus somente possibilitasse uma compreensão "equívoca" da realidade, isto tornaria este conceito um equivalente de falsa consciência ou ideologia no sentido de concepção mistificada e mistificadora da realidade, fazendo com que a ruptura das regras se desse mediante uma desalienação dos agentes. De modo bastante distinto, o conceito de habitus possibilita toda uma tentativa de compreensão da presença de formas de exercício do poder - portanto de domínio que exigem uma igualmente mais complexa compreensão das determinações resultantes da posição de classe.
} 
da condição de classe, a obra de Bourdieu encontra-se implicitamente permeada pelo sentido da historicidade.

Esta característica permitiu a Bourdieu conceber tanto a ruptura transgressiva como a reordenação inovadora das regras sociais sem cair nos logros da ingenuidade voluntarista ${ }^{12}$. E, por consequência, ter por pressuposto que a análise sociológica soe ser feita mediante o reconhecimento e a compreensão da gênese dos dispositivos pelos quais todo agente realiza, sob os limites dos sistemas de representações simbólicas aos quais está objetivamente vinculado, uma leitura da realidade, Leitura que em princípio deve-lhe ser orientadora das suas práticas, de suas ações e discursos.

Para a compreensão da gênese desses dispositivos deve-se atentar para o fato, o qual escapa a perspectivas centradas apenas nas condições intrínsecas de classe, de que as inter-relações entre campos e habitus nos permitem conceber as propriedades dos agentes sociais não como unicamente provenientes da sua condição objetiva de classe, como se essas propriedades fossem universais, transculturais e transhistóricas.

Essas perspectivas terminam por secundarizar os efeitos de distinção e identificação provenientes, primeiro, das posições desses agentes nas estruturas singulares de cada campo; segundo, das relações entre os campos e em terceiro lugar, dos aspectos de ordem nacional da constituição dos campos sociais (BOURDIEU, 1983b). Em particular, as singularidades históricas dos processos geradores da autonomia de um campo em relação a outros campos e, por decorrência, da cultura política dos agentes sociais.

Se é indispensável em uma análise relacional a construção de homologias entre estruturas de campos diferentes a fim de que, mediante comparações entre agentes que ocupam posições semelhantes em estruturas diferentes, se obtenha um melhor entendimento do objeto que se pretende conhecer e, obrigatoriamente, do campo em que este se inscreve, é preciso também sempre ter em vista a diferença entre a homologia de posição e a condição de classe, pois por um equívoco analítico, podem vir a ser considerados como idênticos agentes que, embora posicionados de modo similar em uma dada estrutura, são, por força das características atinentes às suas condições históricas de classe, desiguais (BOURDIEU, 1991).

Exemplo deste tipo de equívoco é a atribuir uma identidade de classe própria ao operariado a agentes sociais pertencentes a camadas das "classes médias", mas que vivenciam processos de pauperização, como, por exemplo, os professores brasileiros da educação básica. Ou, em sentido inverso, tomar como membros das "classes médias", integrantes de segmentos proletarizados que ampliaram seus padrões de consumo a partir do aumento de suas rendas, como ocorreu recentemente no período 2007

\footnotetext{
12 Há neste aspecto, sem dúvida, uma aproximação de Bourdieu com perspectivas fenomenológicas, contrariando outro entendimento equivocado de sua obra, a qual advoga uma incompatibilidade entre a sua análise e preocupações da tradição do pensamento marxista no tocante à problemática da transformação social, inclusive porque a análise marxista não mostra grande apreço ao desejo voluntarista, ainda que o próprio Marx por vezes louvasse a impetuosidade política, como no caso da Comuna de Paris.
} 
a 2013. Ambos equívocos conceituais provocados por leituras eivadas de esquematismos políticos, uns aparentemente à esquerda e outros, claramente à direita e conservadores.

Porém, independentemente das analogias e comparações que possam ser feitas entre campos sociais visando à necessária apreensão de similaridades estruturais quanto a posição e condição de classe dos agentes e à gênese de seus dispositivos, sabemos que as situações sociais vivenciadas pelos agentes não são historicamente idênticas. É possível, portanto, a ocorrência de uma inadequação das disposições dos agentes, presentes no acervo do capital cultural dado pelo seu habitus, às novas situações.

A inadequação das interpretações e práticas socialmente apreendidas para a realização dos seus objetivos "obriga" aos agentes sociais a procederem, ainda que seja pequena a margem de autonomia, com maior liberdade ante as orientações para a ação tradicionalmente transmitidas. Especialmente quando ocorrem situações inéditas e inexistem formas historicamente consagradas de ação, intensificamse, contrapondo-se ao que seria aparentemente um destino estruturalmente determinado, as possibilidades de flexibilização do agir dos agentes, "que embora, não sejam produto de uma aspiração consciente de fins explicitamente colocados a partir de um conhecimento adequado das condições objetivas, nem de uma determinação mecânica de causas, mostram-se objetivamente ajustadas à situação" (BOURDIEU, 1989, p. 23). Isto faz das práticas sociais, sobretudo dos que possuem posições elevadas no campo, um exercício de estratégias diuturnas para assegurar as suas posições ou galgar outras ainda mais elevadas, mas também possibilita aos socialmente subalternos empreender estratégias para alterar, em algum grau, a condição dominada a que estão submetidos.

No entanto, a perspectiva da flexibilização das ações dos agentes não deve conduzir-nos, enquanto pesquisadores, à crença em formas messiânicas de desvelamento da realidade, estabelecendo como objetivo maior do empreendimento analítico a apreensão de insights "desalienadores", os quais transformariam diametralmente os modos de ação dos agentes. Muito ao contrário, devemos ter como centro de nossa atenção, graças ao privilegiar o conceito de trajetória, a diacronia das relações dos agentes no espaço social, comparando os diferentes momentos dessas relações no interior dos campos.

Ainda que por vezes possa parecer profundamente irracional, seja ao observador imbuído dos pré-julgamentos de sua lógica particular, seja ao ativista político desejoso de instituir, àqueles que aspirar representar, as suas específicas percepções de mundo, as trajetórias (e das lutas e dos esforços que as integram) feitas pelos agentes, principalmente os socialmente subalternos, no intuito da materialização dos interesses que têm por seus, é também a trajetória histórica da produção das reinterpretações que os agentes, motivados por seus interesses nos campos e mediados pelo legado cultural inscrito em seu habitus, fazem da realidade. As reinterpretações da realidade podem ser parte de um concomitante processo de reconfiguração de suas identidades e, similarmente, das de outros agentes com os quais se vêm em relação no interior dos campos ${ }^{13}$.

\footnotetext{
${ }^{13}$ Nessa perspectiva, ganha ainda maior relevância estudos sobre mudanças e permanências de aspectos identitários de agentes sociais subalternos em processos de profunda transformação social, como por exemplo, o clássico trabalho de Florestan
} 
Em virtude da permanente referência ao caráter histórico das estratégias e das trajetórias, portanto implicitamente do habitus de classe e da gênese deste, vem a ser perfeitamente possível fazer-se uma aproximação entre Bourdieu e Gramsci, sobretudo por dois aspectos do pensamento de Gramsci nem sempre devidamente ressaltados por aqueles que se detém sobre suas reflexões a respeito de temas educacionais ou pertinentes às determinações de classe dos intelectuais. Referimo-nos às problemáticas da "herança cultural" dos agentes sociais e do processo "nacional" de constituição dos intelectuais.

\section{Hegemonia e Habitus de classe}

A questão da herança cultural manifesta em Gramsci através de sua sintética expressão "homem bizarro", empregada para assinalar a diversidade de tradições e costumes, formadora do agir e do pensar e da qual os homens são acríticos herdeiros, fazendo-os participantes de "uma concepção de mundo "imposta" mecanicamente pelo ambiente exterior, ou seja, por um dos vários grupos sociais nos quais todos estão automaticamente envolvidos desde sua entrada no mundo consciente" (GRAMSCI, 1999, p. 93).

Esta aproximação é possível, pois, conforme os comentários de Ortiz (BOURDIEU, 1983), acerca das relações entre o babitus e o processo de socialização dos agentes sociais, Bourdieu "considera a socialização como um processo que se desenvolve ao longo de uma série de produções de habitus distintos, dedica-se a uma atenção particular ao período de formação das primeiras categorias e valores que orientam a prática futura do ator" (BOURDIEU, 1983, p. 18). Ora, se os habitus são necessariamente resultados históricos, nem por isto os agentes sociais possuem a dimensão da sua historicidade e da historicidade das práticas, dos valores e das categorias por eles gerados. Portanto, a constituição dessas práticas e a introjeção desses valores e categorias realiza-se com toda a força da internalização primária, organizadora de um primeiro esquema inconsciente de pensar, de identificar, de classificar, enfim de instituir imaginariamente para si a realidade, definindo esta última de forma sincrônica e naturalística, pela simbiose de instrumentos cognitivos de múltiplas temporalidades, tornando os agentes sociais sempre algo "bizarramente" constituídos.

Embora a expressão de Gramsci possa ser entendida unicamente como um sublinhar da necessidade dos integrantes das classes subalternas, que aspiram a romper com a dominação de classe a qual se encontram sujeitados, procederem à superação dessa espécie de bricolage intelectual que é o senso comum, ela, por estar intimamente associada à problemática do exercício da hegemonia, refere-se em última instância às possibilidades das trajetórias (coletivas e individuais) dos agentes sociais, portanto, também aos habitus desses agentes e às suas lutas nos campos sociais. Qual não é a intenção de Gramsci em sua aparente crítica burlesca do lorianismo, senão, primeiro, reafirmar como podem se encontrar,

Fernandes sobre a população negra no Brasil. (Fernandes, 2007). 
subliminarmente presentes na constituição dos habitus dos homens, elementos de enorme força que, à primeira impressão do observador, seriam incompatíveis e chocar-se-iam com as formas reconhecidas como socialmente legítimas de compreensão do mundo e do agir na sociedade.

Esses elementos culturais não imediatamente perceptíveis à consciência dos agentes, dado que o habitus se relaciona ao aprendido inconscientemente em meio aos efeitos das relações entre agentes diferentemente posicionados nos campos sociais, longe de serem apenas características psicológicas de indivíduos particulares, são traços despercebidos ou desconhecidos de seus habitus de classe. Contudo, nem por isto deixam de estar inscritos nas sensações dos corpos e de aflorar em momentos de forte crise social geral como, por exemplo, na conjuntura que antecede à vitória do fascismo e do nazismo (GRAMSCI, 1999). Eles se apresentam nos momentos de grande tensão pela disputa objetiva e conscientemente empreendida por posições nos campos sociais, num contraponto às atitudes mais corriqueiras do cotidiano.

Embora reconhecendo o peso dos determinismos inconscientes aos homens, nem por isto a análise gramsciana, tal como já tantas vezes foi ressaltado, rende-se a um determinismo situado fora do quadro das relações sociais. Na linguagem particular da conjuntura intelectual em que se inscreve, Gramsci procurou sempre viabilizar uma alternativa entre o voluntarismo e o determinismo economicista, a fim de combinar a vontade transformadora do agente com as determinações objetivas do social, buscando solucionar tal antinomia mediante o par liberdade-necessidade.

Neste, liberdade é fruto do exercício crítico da razão, do conhecimento, ou seja, do conhecimento que pretende realizar o conhecer de si mesmo. Seria (ou tentaria ser) livre aquele que conhece as determinações que pesam sobre si, em última instância sobre o seu habitus. Temos aqui significativos pontos de contato com os inúmeros comentários de Bourdieu acerca da importância do esforço de objetivação daquele que se esforça por construir um conhecimento o mais objetivo possível, exigindo desde sempre o empreender a auto-objetivação de si.

Aproxima-se assim, o pensamento gramsciano do caráter libertário, emancipatório e desmistificador que deve acompanhar, para Bourdieu, toda a reflexão sociológica não espontaneísta. Eis, sob outra roupagem, o "escapar à história", a recusa à aceitação e à legitimação do que é socialmente imposto e apresentado como fatalidade natural.

\section{Observações finais}

Nas sociedades modernas concomitantemente ao capitalismo e ao processo de individuação, vieram a se constituir modos expressivamente mais complexos e diferenciados de exercício do poder. Nestes, as formas de comunicação inter e intraclasses se diversificaram, fazendo prevalecer um novo modo de vida e de domínio social, de "brutal coerção psicológica e moral" e de universal disciplinarização: os processos de hegemonia. 
Não há possibilidade de hegemonia sem a formação de hábitos e costumes (uma "reforma moral e intelectual" para empregar-se uma conhecida expressão gramsciana). Hábitos que não são apenas o resultado imediato e mecânico de determinadas condições econômicas, mas, como salientou Norbert Elias (ELIAS, 1991), a decorrência final de processos longo de geração, que gradativamente foram disseminados e assimilados por vias institucionais.

Porém, isto não significa considerar que a hegemonia seja, em primeiro lugar, a imposição absoluta e total dos intuitos, valores e percepções dos socialmente dominantes. Ao contrário, aqueles que almejam exercê-la devem necessariamente considerar os interesses e as tendências dos grupos sobre os quais ela será exercida, procurando construir certo compromisso, a partir do sacrifício de aspectos nãoessenciais dos seus próprios interesses.

Em segundo lugar, e por decorrência, a hegemonia não vem a ser também uma aceitação passiva e sem ambições, por parte dos socialmente subalternos, das situações sociais em que se encontram. $\mathrm{O}$ que, antes de tudo, a conformação de um processo hegemônico propicia é o reconhecimento, como naturais (mesmo quando podem ser estas consideradas moralmente injustas ou desumanas), das regras fundamentais da sociedade em que os agentes se encontram. O reconhecimento da naturalidade das regras sociais não é sinônimo de um conformismo imobilista. Pode mesmo vir a ser um elemento de impulsão para a transformação (particular ou individual, principalmente) das condições imediatas de existência dos agentes sociais. A legitimidade das regras sociais e sua "adesão consciente" somente se fazem possível pela disposição por uma classe social dos recursos e condições intelectuais e morais para a produção da aceitação do modo de existência social em vigor. Tais recursos e condições na configuração específica da modernidade se viabilizaram mediante a gradual conformação de inéditos, tanto de uma perspectiva quantitativa quanto qualitativa, dados os seus graus de abrangência e dimensão de controle, aparatos burocrático-intelectuais estatais e suas redes de funcionários.

Sabemos que a existência desses aparatos burocrático-intelectuais proporcionou a ocorrência do fenômeno da "produção" - via instituições escolares - de novas formas de "trabalho intelectual" e de intelectuais em "massa". As novas necessidades de atendimento às atividades administrativas ou de serviços, ampliaram, mesmo que seletivamente, a universalização do acesso aos sistemas de ensino e igualmente aumentando a permanência dos agentes sociais, inclusive os subalternos e dominados, em seu interior.

Processa-se, há décadas, uma intensificação, com maiores ou menores momentos de exacerbação, da ocorrência de contradições anteriormente desconhecidas nas instituições de ensino e nos campos intelectual, científico e educacional. Todavia, mesmo vindo a ser mais comuns, essas contradições não se manifestam de maneira igual em todas as sociedades modernas. As circunstâncias nacionais definem muito diferenciadamente as suas formas e características, fazendo com que a morfologia desses campos apresente especificidades nacionais bastante relevantes. Novamente, pelo ressaltar das singularidades nacionais dos campos sociais, verificamos proximidades nas reflexões de Gramsci e de Bourdieu. Ambos 
assinalaram a importância das condições particulares nacionais para a definição - e entendimento - do modo de constituição do campo intelectual e do campo científico, aos quais está intrinsecamente relacionado o campo educacional. O emprego articulado de seus conceitos amplia as possibilidades de entendimento das transformações em curso no espaço social e nos diferentes campos que o constitui, em especial, o campo educacional, sobretudo nas sociedades periféricas e dependentes.

\section{REFERÊNCIAS}

BACHELARD, G. O Racionalismo Aplicado. Tradução de Nathanael C. Caixeiro. Rio de Janeiro: Zahar Editores, 1977.

BACHELARD, G. A Epistemologia. Tradução de Fátima Lourenço Godinho e Mário Carmino Oliveira. Lisboa: Edições 70, 1984.

BACHELARD, G. O Materialismo Racional. Tradução de João Gama. Lisboa, Edições 70, 1990.

BOURDIEU, P. A Economia das Trocas Simbólicas. Tradução e organização de Sérgio Micelli. São Paulo: Ed. Perspectiva, 1982.

BOURDIEU, P. Sociologia. Organizador Renato Ortiz. Tradução de Paula Montero e Alícia Auzmendi. São Paulo: Ática 1983.

BOURDIEU, P. Questões de Sociologia. Tradução de Jeni Vaistman. Rio de Janeiro: Editora Marco Zero, 1983b.

BOURDIEU, P. O Poder Simbólico. Tradução de Fernando Tomaz. Rio de Janeiro/Lisboa: Bertrand Brasil/DIFEL, 1989.

BOURDIEU, P. Coisas Ditas. Tradução de Cássia R. da Silveira e Denise Moreno Pegorim. São Paulo: Ed. Brasiliense, 1990.

BOURDIEU, P. O Senso Prático. Tradução de Maria Ferreira. Petrópolis: Vozes, 2009.

BOURDIEU, P. e CHARTIER, R. O Sociólogo e o Historiador. Tradução de Guilherme João de Freitas Teixeira. Belo Horizonte: Autentica, 2011.

BURAWOY, M. O Marxismo Encontra Bourdieu. Tradução de Fernando Rogério Jardim. Campinas: Editora da Unicamp, 2010.

ELIAS, N. A Condição Humana. Tradução de Manuel Loureiro. Lisboa: DIFEL; Rio de Janeiro: Bertrand Brasil, 1991.

FERNANDES, F. O Negro no Mundo dos Brancos. São Paulo: Global, 2007. 
FERRY, Luc e REBAUT, Alain. Pensamento 68. Ensaio sobre o anti-humanismo contemporâneo. Tradução de Roberto Markenson e Nelci Nascimento Gonçalves. São Paulo: Ensaio, 1988.

GRAMSCI, A. Cadernos do Cárcere. Volume 1. Tradução de Carlos Nelson Coutinho. Rio de Janeiro: Civilização Brasileira, 1999.

KHUN, Thomas S. A Estrutura das Revoluções Científicas. Tradução de Beatriz Vianna Boeira e Nelson Boeira. São Paulo: Ed. Perspectiva, 1987.

MARX, K. O 18 Brumário e Cartas a Kugelmann. Tradução Leandro Konder e Renato Guimarães. São Paulo, Rio de Janeiro: Paz e Terra, $7^{a}$ edição.

THOMPSON, E. P. A Miséria da Teoria ou Um Planetário de Erros: Uma crítica ao pensamento de Althusser. Tradução de Waltensir Dutra. Rio de Janeiro: Zahar Editores, 1981. 